\title{
CELL-SCAFFOLD INTERACTIONS IN THE BONE TISSUE ENGINEERING TRIAD
}

\author{
Ciara M. Murphy',*, Fergal J. O’Brien ${ }^{3}$, David G. Little ${ }^{1,2}$ and Aaron Schindeler ${ }^{1,2}$ \\ ${ }^{1}$ Orthopaedic Research and Biotechnology Unit, The Children's Hospital at Westmead, Sydney, Australia \\ ${ }^{2}$ Discipline of Paediatrics and Child Health, Faculty of Medicine, University of Sydney, Sydney, Australia \\ ${ }^{3}$ Department of Anatomy, Royal College of Surgeons in Ireland, Dublin, Ireland
}

\begin{abstract}
Bone tissue engineering has emerged as one of the leading fields in tissue engineering and regenerative medicine. The success of bone tissue engineering relies on understanding the interplay between progenitor cells, regulatory signals, and the biomaterials/scaffolds used to deliver them otherwise known as the tissue engineering triad. This review will discuss the roles of these fundamental components with a specific focus on the interaction between cell behaviour and scaffold structural properties. In terms of scaffold architecture, recent work has shown that pore size can affect both cell attachment and cellular invasion. Moreover, different materials can exert different biomechanical forces, which can profoundly affect cellular differentiation and migration in a cell type specific manner. Understanding these interactions will be critical for enhancing the progress of bone tissue engineering towards clinical applications.
\end{abstract}

Keywords: Tissue engineering; bone; regeneration; scaffold; cell-scaffold interactions.

*Address for correspondence:

Ciara M. Murphy

Orthopaedic Research and Biotechnology, Research Building

The Children's Hospital at Westmead, Locked Bag 4001

Westmead, NSW 2145, Australia

Telephone Number: +61-2-98452985

FAX Number: +61-2-98453078

E-mail: ciara.murphy@sydney.edu.au

\section{Introduction}

The human body's natural reaction to trauma or injury is to initiate a cascade of biological processes leading to tissue repair. Bone tissue has excellent regeneration ability whereby it can repair itself in response to trauma or injury. However, if injury exceeds a critical size, bone formation is impaired and surgical intervention is required. There are a number of therapeutic strategies for promoting bone tissue regeneration. One prevalent approach is to transplant healthy autogenous tissue or tissue allograft. While significant technical advances continue to be made in transplantation treatments, the idea of tissue replacement dates back to the $16^{\text {th }}$ century. Gasparo Tagliacozzi (1546-99) published 'De Curtorum Chirurgia per Insitionem' (The Surgery of Defects by Implantation) in 1597, in which he described a nose replacement that he had constructed from an autogenous forearm flap (Murphy and O'Brien, 2010; O'Brien, 2011). Today, autografts are still widely utilised for bone grafting while allografts tend to be applied more for whole organ restoration such as the liver, kidney and heart. Despite the life-saving capacity of tissue grafting, major problems still exist. For autogenous grafts, tissue and donor site morbidity can be problematic. For allografts, immune complications and donor availability remain challenging (Damien and Parsons, 1991; Arrington et al., 1996; Giannoudis et al., 2005; Khan et al., 2005). In light of these obstacles, there is a strong need for the development of novel synthetic or bioengineered bone graft substitutes.

Recent scientific progress in biomaterials and cell based therapeutics has created exceptional advances in the development of engineered tissues. There are three main components in the field of tissue engineering:

1. A scaffold that provides structure and substrate for tissue growth and development

2. A source of cells to facilitate required tissue formation

3. Growth factors or biophysical stimuli to direct the growth and differentiation of cells within the scaffold.

Taken together, these components make up what is known as the tissue engineering triad (Fig. 1).

Despite early successes achieved with tissue engineering, many challenges are still faced in tissue regeneration (Rose and Oreffo, 2002). Clearly, it is critical to tailor the components of the tissue engineering triad for specific tissue applications. However, not only are these components individually important, understanding their interactions is key for successful tissue engineering. It is the purpose of this review to focus on the interplay between the three components of the tissue engineering 


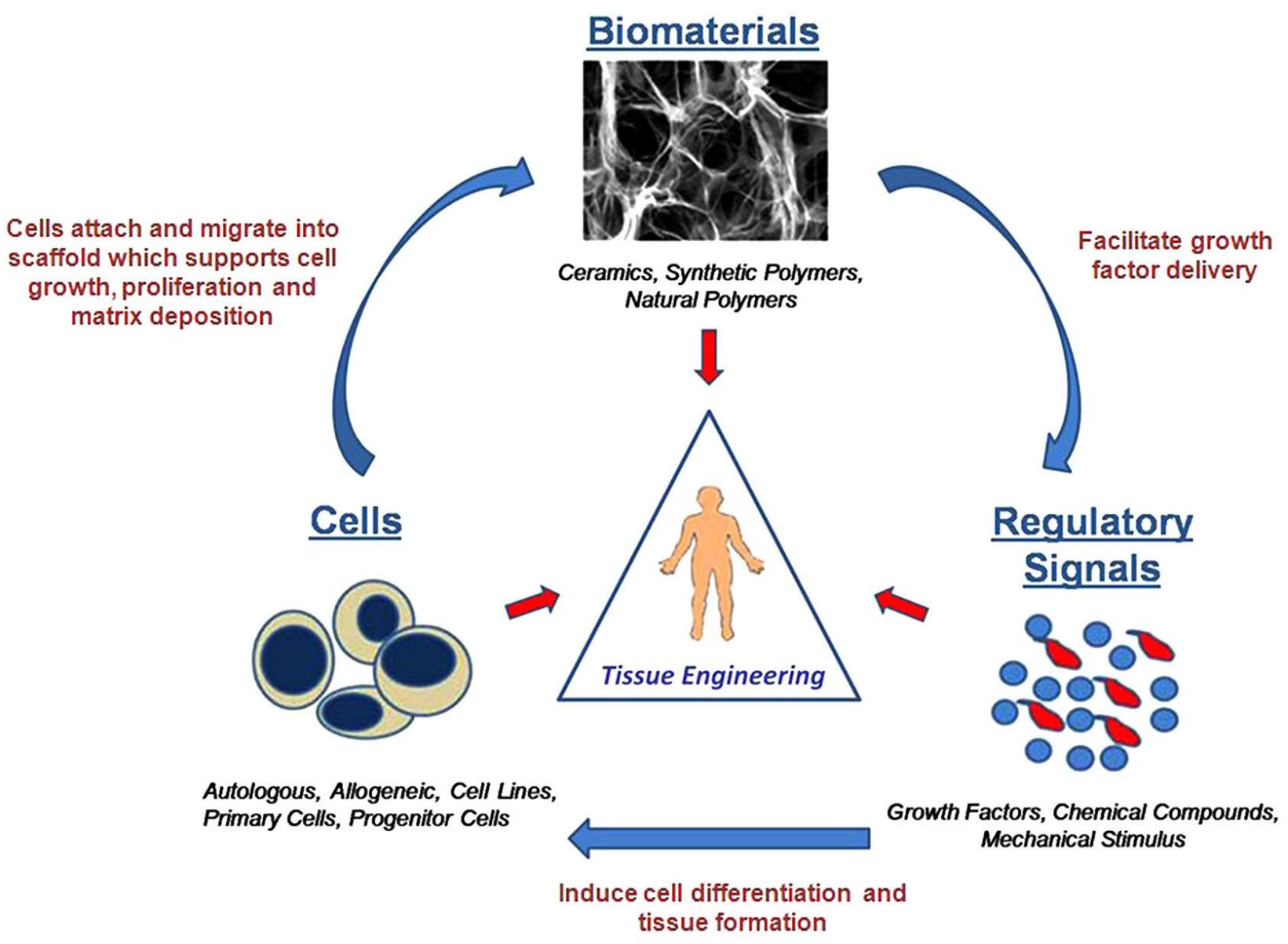

Fig. 1. The three essential components that make up the tissue-engineering triad.

triad in the context of bone tissue engineering, with particular emphasis on the importance of scaffold design on cell attraction, migration, differentiation, and their subsequent tissue generation.

\section{Biomaterials}

Over the past several decades there has been an explosion in the range of available scaffolds in terms of composition and architecture to promote osteoconduction (bone mineral and collagen deposition) and osteoinduction (osteogenic differentiation) (Albrektsson and Johansson, 2001). In the field of scaffold design, crucial considerations include the biocompatibility and biodegradability of the biomaterial used (Hutmacher, 2000; Yang et al., 2001). The term biocompatible refers to the ability of a scaffold to support cell growth and tissue regeneration in vivo, without eliciting an inflammatory or immunogenic response that may result in its rejection. Limited local inflammation can promote healing and neovascularisation, however chronic inflammation and/or an adverse immune response can compromise both the implant and the patient (Babensee et al., 1998; Hutmacher, 2000). Ideally, biodegradation should occur over a period of time that allows the scaffold to disappear in concurrence with tissue formation, leaving behind repaired or regenerated tissue. This negates the need for a second surgery to remove the implant (Murphy et al., 2000; Haugh et al., 2011). In the case of drug delivery, degradation needs to be controlled at a rate that can facilitate optimal drug release. The choice of material and the micro- and macro-structure of that material will influence the biocompatibility and degradability. There are three major classifications of materials that have been used for scaffolds in bone tissue engineering: (1) ceramics, (2) synthetic polymers and (3) natural polymers.

Ceramics are non-metallic compounds with a crystalline structure. Typically, they have a high level of stiffness and as a result are commonly used in bone tissue engineering. The most frequently used ceramics are calcium phosphate $(\mathrm{CP})$, tricalcium phosphate $(\beta-\mathrm{TCP})$, and hydroxyapatite (HA), and these materials are biocompatible and osteoconductive. Their biocompatibility is commonly attributed to their structural similarities to the mineral phase of bone. Nevertheless, ceramics are brittle materials and generally have a slow rate of degradation and can persist for months or years (Pilliar et al., 2001; Rizzi et al., 2001; Giannoudis et al., 2005).

A number of synthetic, degradable polymers have been employed for bone tissue engineering. Poly(alpha-hydroxy 
acid) polymers such as polylactic acid (PLA), polyglycolic acid (PGA), and the co-polymer poly-DL-lactic-co-glycolic acid (PLGA) have shown promising pre-clinical and clinical findings (Amanat et al., 2007). For PLGA, the physical properties and degradation rates can be controlled by altering the monomer ratios in lactide/glycolide copolymers. These polymers also have FDA approval for specific clinical applications (Yang et al., 2001; Jiang et al., 2006). An attraction of synthetic polymers is an ability to manufacture scaffolds with characteristics tailored to match that of new tissue formation. However, a major disadvantage with many synthetic polymers is the release of acidic degradation by-products that can alter the $\mathrm{pH}$ in surrounding tissue. In turn, this can cause adverse tissue and inflammatory reactions (Yang et al., 2001; Ravindran et al., 2010).

Natural polymers commonly used in tissue engineering include collagens, glycosaminoglycan, chitosan, hyaluronic acid, fibrin and elastin (Berglund et al., 2004; Ma et al., 2004; Glowacki and Mizuno, 2008; Murphy et al., 2010), isolated directly from the extracellular matrix (ECM). Cell adhesion and subsequent cell activity is mediated by specific integrin-ligand interactions between the cells and their surrounding ECM. Some of these natural polymers contain surface ligands required for cell adhesion and proliferation (Heino, 2000). Those that lack cell specificity are modified to incorporate ligands that facilitate cell-ECM interaction (Vepari and Kaplan, 2007; Kim et al., 2008). Natural polymers present a more native surface relative to synthetic polymers; as a result, they are biocompatible and typically degradable with non-toxic degradation products (Hubbell, 1995). Limitations of natural polymers include their poor mechanical properties that are unsuitable for high strength applications as well as the relatively high costs associated with purification or de novo synthesis. Nonetheless, for orthopaedic applications natural polymers remain a popular choice of material. Collagen has been frequently explored, as it is one of the main constituents of the natural ECM. Outside of orthopaedics, collagen has achieved success in the areas of skin (Yannas et al., 1989), bladder (Atala et al., 2006), and airways (Macchiarini et al., 2008). However, to overcome the limitations associated with natural polymers, recent advances in scaffold design and fabrication have led to a paradigm shift towards the development of biomimetic scaffolds. Biomimetic scaffolds imitate the native ECM and are often utilised in vitro as analogues of the natural ECM to facilitate investigations of cell-ECM interactions and processes (Shin et al., 2002; Ravindran et al., 2010). More importantly, they provide a compromise between the mechanical and biological prerequisites needed to rapidly promote bone healing.

An elaboration of this strategy has been to incorporate an additional phase into collagen scaffolds to improve the osteoconductivity and/or biomechanics. One example is the introduction of a ceramic phase, such as hydroxyapatite (HA) to improve the mechanical properties. Collagenhydroxyapatite (CHA) scaffolds have demonstrated improved healing of bone defects in comparison to collagen alone (Gleeson et al., 2010). However, other biomimetic scaffolds have recently emerged and are drawing new interest in the tissue engineering field (Shin et al., 2003; Radisic et al., 2006; Moutos et al., 2007; Potter et al., 2008).

\section{Cells in Tissue Engineering}

In the context of bone tissue engineering, regeneration is biologically driven by progenitor cells that are able to form new osteoblasts. These progenitors can arise from within the damaged tissue or surrounding native tissues, or they can be exogenously supplied as part of the tissue engineering solution.

An important consideration for the delivery of ex vivo cells is whether they are autologous, allogenic or xenogenic. Autologous cells are harvested directly from the individual undergoing repair, whereas allogenic cells are from a donor individual (of the same species). Xenogenic cells are transplanted from a different species and are less common in tissue engineering than in the field of whole organ transplantation.

There are three principal cell therapeutic strategies for treating diseased or injured tissues in patients: (1) implanting isolated cells, (2) implanting a construct assembled from cells and scaffolds, or (3) in situ tissue regeneration by native cells.

\section{Implantation of isolated cells}

With this strategy, whole cell populations can be directly transplanted or isolated cells can be cultured and expanded ex vivo prior to re-implantation. Raw bone marrow transplants are an example of the former and have been used in the treatment of a variety of malignant and non-malignant haematological diseases. Cells within the marrow have the ability to reconstitute the haematopoietic system (Takahashi and Yamanaka, 2006) and the stromal progenitors are multipotent and can differentiate into a variety of cell lineages (Pittenger et al., 1999). Consequently, transplanted marrow cells have been used in the regeneration of a range of complex organs including the liver and heart (Caplan, 2007; Timmins et al., 2007). Recently, Gao et al. (2012) demonstrated the use of implanted isolated mesenchymal stem cells (MSCs) for bone tissue engineering. MSCs isolated from healthy donor mice were implanted into mutant littermates that exhibited skeletal defects similar to those seen in ageing bone and enhanced implant osteointegration (Gao et al., 2012).

\section{Implanting a construct assembled from cells and scaffolds}

In the context of tissue engineering and regenerative medicine, the use of isolated cells is not limited to direct replacement of damaged cells. Another method is to deliver a combination of whole cell isolates or ex vivo cultured cells seeded onto a substrate template (Lee et al., 2003; Levenberg et al., 2003; Kim et al., 2010). Aside from implantation outcomes, implant designs are still commonly assessed in vitro using 3D culture systems. These 3D culture systems can utilise primary cells from 
the tissue to be regenerated, isolated stem/progenitor cells, or immortalised cell lines. These systems have been used to gauge the performance of engineered constructs and achieve incremental improvements by modification of scaffold (porosity, architecture, and biomaterials), drug delivery, or cell source.

Established cell lines capable of extensive or indefinite proliferation are frequently used for in vitro investigations. While cell lines can demonstrate biocompatibility, these lines are by definition abnormal and may poorly reflect the in vivo behaviour of a tissue implant. Primary cells derived from tissue explants (whether mechanically or enzymatically isolated) can provide a pool of cells more comparable to endogenous progenitors. Nevertheless, $3 \mathrm{D}$ culture models with primary cells allow optimisation without complications such as post-surgical infection and host versus graft disease (HVGD). For some tissues, primary cells can be challenging or impossible to isolate and expand (such as pancreatic islet cells), but this is rarely a problem for bone.

For bone tissue engineering purposes, bone marrowderived MSCs remain popular due to their multipotency. They are capable of differentiation down multiple lineages including bone, cartilage, and adipose tissue (Pittenger et al., 1999; Krampera et al., 2006; Uccelli et al., 2008). Bone marrow is also considered to be the most accessible and enriched source of adult stem cells. Pittenger et al. (1999) demonstrated that cells isolated from human marrow aspirates were capable of remaining in a stable undifferentiated state in long-term cultures and could be induced towards osteochondral lineages when provided with the appropriate cues (Pittenger et al., 1999). Since then, extensive investigations have been carried out in terms of MSC characterisation and clinical potential. However, there are disadvantages associated with the use of bone marrow derived MSCs. The harvest of these cells is an extremely invasive procedure with donor variability being a prevalent issue. Furthermore, the number, differentiation potential and life span of these cells can decrease with increasing age (Nishida et al., 1999; Mueller and Glowacki, 2001; Stenderup et al., 2003). Adipose tissue has also been shown to contain a population of multipotent cells, genetically similar to MSCs known as adipose derived stem cells (ADSCs). ADSCs are easily extracted from adipose tissue after surgical procedures such as liposuction (Fraser et al., 2008) and similarly to MSCs, can differentiate towards an osteogenic lineage when treated in osteogenic medium (Zuk et al., 2002) or genetically modified to over-express BMP-2 (Dragoo et al., 2005). An alternative, albeit heterologous, source is umbilical cord blood which can be harvested by a non-invasive approach. Similar to bone marrow and adipose tissue, umbilical cord blood has a population of multipotent MSCs that can be differentiated down an osteogenic lineage (Kern et al., 2006). However, the number of MSCs in the umbilical cord blood is extremely low in comparison with their population in the bone marrow, adipose tissue and more difficult to isolate (Musina et al., 2007).

Human ES cells are a broader utility as they maintain pluripotency, can be induced into multiple mature somatic cell types (Rippon and Bishop, 2004) and can be cultured indefinitely in an undifferentiated state due to their ability to self-renew (Bishop et al., 2002; Hipp and Atala, 2008). However, the use of these cells is often coupled with complex ethical, religious, and political issues (Rippon and Bishop, 2004), leading to the search for alternate sources of stem cells that could be derived without creating or destroying embryos (Hipp and Atala, 2008). In 2006, Takahashi and Yamanaka attempted to circumvent the ethical issues associated with ES cells. They reported that enforced expression of 4 key transcription factors (OCT3/4, Sox2, Klf4 and c-Myc) could re-program somatic cells to pluripotency with similar developmental potential as ES cells (Takahashi and Yamanaka, 2006). These cells were termed induced pluripotent stem (iPS) cells. However, the vast differential potential of ES and iPS cells is assessed by the ability of these cells to form teratomas (Thomson et al., 1998; Yu et al., 2007; Zhang et al., 2008). Consequently, the use of these cells in clinical practice is thus far hindered.

\section{In situ tissue regeneration by native cells}

The isolation and expansion of autologous stem cells was once considered to be the future of tissue engineering and regenerative medicine. However, challenges associated with cost and culture times as well as limited demonstrations of efficacy have led to a re-focusing of efforts to recruit native cells to sites of tissue damage. In order to modulate the migration and tissue-appropriate differentiation of endogenous progenitors, drugs capable of affecting regulatory signals or proteins involved with the regulatory signalling cascade can be locally delivered. As such, the field of controlled drug delivery via tailored biomaterials is currently driving many innovations in biomaterials (Numata and Kaplan, 2010; Yu et al., 2010; Hoffman, 2012; Panyam and Labhasetwar, 2012;).

Another method for modulating progenitor recruitment and differentiation is the application of gene therapy technologies. Gene therapy is a powerful tool for the manipulation of existing progenitors as well as the delivery of paracrine signals (Godbey and Atala, 2002). For example, cells can be engineered to produce VEGF to stimulate angiogenesis or rhBMP-2 to promote osteoblastogenesis. Gene therapy with viral and non-viral vectors can allow the transient or sustained release of a range of therapeutic factors, albeit often at high cost and some concerns for malignant transformation (Levenberg et al., 2003). Recently, there has been a surge in research to combine gene therapy with scaffold-based templates to produce gene-activated matrices (GAMs), enhancing the capacity for repair. The scaffold acts as a depot for the gene while simultaneously providing both structural support and a matrix for new tissue deposition (Storrie and Mooney, 2006; O'Rorke et al., 2010; Curtin et al., 2012; Tierney et al., 2012a).

\section{Regulatory Signals}

Cellular behaviour is strongly influenced by biological, biochemical, and biophysical cues from the ECM. Consequently the use of regulatory signals is the third component of the tissue engineering triad. These include 
biochemical and or biophysical stimuli to induce and regulate tissue formation both in vitro and in vivo.

Biochemical stimuli modulate cell-signalling processes that regulate cellular migration, adhesion, proliferation, differentiation, and survival. Growth factors and cytokines can function locally or systemically to change patterns of gene expression in target cells. They can also be involved with up-regulating and down-regulating the synthesis of other growth factors and receptors. These proteins bind to transmembrane receptors that transduce extracellular signals to changes in gene expression (Griffith and Naughton, 2002; Rose and Oreffo, 2002; O’Brien, 2011). Growth factors and drugs that modulate growth factor signalling are broadly used within the tissue engineering field, although the use of recombinant factors can significantly add to the cost of an implant.

For bone tissue engineering, rhBMPs are approved for clinical intervention and can create new bone de novo (Geiger et al., 2003). Other growth factors used to promote bone include the Insulin-like Growth Factors (IGFs) and Transforming Growth Factor- $\beta$ proteins (TGF- $\beta$ s). IGF-I and IGF-II have essential roles in bone growth, development, remodeling and repair. TGF- $\beta$, initially purified from platelets, stimulates matrix protein synthesis, has dramatic effects on osteoblast and osteoclast activity (Bonewald et al., 1990). Blood platelets are also a rich source of platelet-derived growth factor (PDGF), a potent stimulant of mesenchymal cell proliferation and migration such as fibroblasts and vascular smooth muscle cells (Kilian et al., 2004).

Calcium phosphate ceramics can themselves be a regulatory signal in terms of bone tissue engineering. $\mathrm{CP}$ ceramics have a compositional resemblance to bone mineral, as such, the degradation of such biomaterials can elicit a biological response similar to the one generated during bone remodelling (Barrere et al., 2006). The calcium and phosphate ions released during degradation can induce bone cell activity (Zaidi et al., 1989; Kanatani et al., 1991) and may also be used as raw materials for new bone formation (Metsger et al., 1993; Bohner et al., 2012).

In addition to biochemical signals, cellular behaviour is strongly influenced by biomechanical stimuli by a process known as mechano-transduction. Multiple systems have been developed to induce different types of physical stimulation to cells in culture including spinner flask bioreactors, flow perfusion bioreactors, dynamic compression bioreactors, and hydrostatic pressure bioreactors (Darling and Athanasiou, 2003). Provision of appropriate biomechanical stimulation ex vivo can positively influence cell differentiation and the production of ECM and ultimately the outcome following implantation (Plunkett and O'Brien, 2011). Optimised biomechanics can also be used to improve the cellular spatial distribution (Khan et al., 2005). Heterogeneous cell distribution can be a major obstacle to developing any three-dimensional (3D) tissue or organ ex vivo.

A greater understanding of the role of the ECM in coding molecular/ biochemical as well as physical information is enabling the development of a new generation of biomaterials. For example, stem cell fate has been shown to be influenced by the stiffness of the substrate on which they reside (Harley et al., 2007; Murphy et al., 2012). As a result, scaffolds themselves have become incorporated as regulatory signals in the development of tissue engineered constructs, whereby the physical and chemical structure of the biomaterial is tailored for optimal cell behaviour.

\section{Cell-Scaffold Interactions for Bone Tissue Engineering}

Optimising the design of bioactive scaffolds is guided by an understanding of the behaviour and responses of cells cultured on these scaffolds. In the past decade, there have been many significant advances in the development of synthetic and naturally occurring biomaterials. However, for bone tissue engineering two major challenges exist. Firstly, it remains difficult to fabricate cell-permissive internal architectures for some biocompatible materials. Insufficient pore structure can lead to cellular aggregations around the periphery of the construct. This in turn can lead to premature core degradation of the construct (Kelly and Prendergast, 2004). Secondly, many scaffolds, particularly those based on first generation designs, have suboptimal mechanical properties, limiting their use in load bearing orthopaedic applications. It is necessary to overcome these challenges in order to facilitate the migration and proliferation of osteoprogenitors, and to support their subsequent differentiation and matrix deposition. As such, the interaction between scaffold architecture, scaffold biomechanical properties, and the cellular response remain areas of emerging importance in the tissue-engineering field.

\section{Cell-ECM interaction}

The chemical composition and physical properties of the natural ECM have been shown to prominently influence cell morphology, motility, and migration (Friedl et al., 1998; Harley et al., 2008; Kanungo and Gibson, 2010). Similar to natural ECM, tissue engineering scaffolds can influence the cellular response in terms of cell proliferation and differentiation (osteoinduction), and the biomaterial and microarchitecture can influence chemo-attraction, adhesion, and migration which in turn will affect matrix deposition and mineralisation (osteoconduction) (Zeltinger et al., 2001; Tierney et al., 2009b;Keogh et al., 2010; Ravindran et al., 2010).

Cell motility and migration play an important role in many biological processes and requires a dynamic interaction between the cell, its substrate and the cytoskeleton (Huttenlocher et al., 1995; Lauffenburger and Horwitz, 1996; Ridley et al., 2003). This occurs by means of specific ligand-integrin interactions. Cell-ECM interactions are accompanied by cytoskeletal action, matrix remodelling, and contraction, which modulate cell fate (Friedl et al., 1998). Whilst cell mediated contraction is a natural phenomenon that is essential for wound healing (Yannas, 2001), it can negatively affect tissue engineered constructs. In mechanically weak scaffolds, such as many natural polymers, it can lead to reduced scaffold volume. 
This can lead to improved biomechanics, but the reduced scaffold size and porosity can result in difficulties fitting specific implant sites and subsequent osteointegration, as well as affecting the cellular response (Lee et al., 2001; Govender et al., 2002).

The discovery of integrins in the mid 1980s altered our view of the natural ECM in terms of its role in the physical linkage and subsequent behaviour of cells (Hynes, 1987). Several parameters contribute to the strength of integrinligand mediated cell adhesion. These include concentrations of adhesive ligands or substrate, number of receptors, and the receptor-ligand affinity. A shift in these parameters can have a dramatic effect on cell migration (Huttenlocher et al., 1995; Gumbiner, 1996; Huttenlocher et al., 1996; Lauffenburger and Horwitz, 1996). Altering ligand density has been observed to affect the strength of the cell-substrate interactions via differential integrin binding to adhesion ligands. In recent years, these effects have been translated in terms of 3D scaffold design. Changing the composition of biomaterials used in scaffold fabrication can lead to a difference in ligand availability and subsequent integrin binding. Tierney et al. (2009) demonstrated that altering the concentration of collagen and glycosaminoglycans (GAGs) in a collagen-GAG scaffold had a significant influence on osteoblast activity, indicating an effect of differing ligand availability (Tierney et al., 2009a; Tierney et al., 2012a). Furthermore, altering the composition of biodegradable scaffolds developed for cartilage repair has led to improved in vivo stability and increased matrix deposition (Moutos et al., 2007). Consequently, the composition of scaffolds in terms of ligand density and availability is an important consideration in scaffold design.

\section{Scaffold architecture}

Pore size, pore interconnectivity, and total porosity are essential considerations in scaffold development. Interconnection is essential for healthy cellular invasion, growth, and nutrient flow. Since the 1970s, scaffold and biomaterial pore size has been recognised as an essential consideration in tissue development (Hulbert et al., 1970). If the pores are too small, cell migration is limited resulting in the formation of a cellular capsule around the edges of the scaffold. This in turn can limit diffusion of nutrients and removal of waste resulting in necrotic regions within the construct. Conversely, if the pores are too large there is a decrease in surface area which in turn limits cell adhesion. Pore size has been observed to influence significantly cell adhesion in vitro (O'Brien et al., 2005). Additionally, scaffold mean pore size significantly affects cell morphology and phenotypic expression (Nehrer et al., 1997).

However, over the years it became evident that the optimal pore size varies depending on the biomaterials used and application of the construct. For example, in porous silicon nitride scaffolds pore sizes in the range of $30-80 \mu \mathrm{m}$ were optimal for endothelial cell adhesion, but fibroblasts preferentially bound to larger pores $(<90 \mu \mathrm{m})$ (Salem et al., 2002). In contrast, for PLLA scaffolds pore sizes of 63 $150 \mu \mathrm{m}$ represented the optimal range for vascular smooth muscle cells, while fibroblasts could bind a wider range of pore sizes including smaller pores $(38-150 \mu \mathrm{m})$ (Zeltinger et al., 2001). However, over the years pores sizes in the range of 20-1500 $\mu \mathrm{m}$ have been reported favourably within the literature (Hulbert et al., 1970; Nehrer et al., 1997; Lee et al., 2004; Williams et al., 2005).

In an effort to reconcile the conflicting reports, O'Brien et al. (2005) developed a method for identifying the specific surface area available for cell adhesion within a collagen-GAG scaffold as it related to pore-size. It was determined that both specific surface area and cell attachment decreased with increasing pore size within a range of 96-150 $\mu \mathrm{m}$ (O'Brien et al., 2005). A more recent study expanded the range to $85-325 \mu \mathrm{m}$ and demonstrated a bimodal effect of pore size on cell attachment (Murphy et al., 2010). Within the lower range of pore sizes (85$190 \mu \mathrm{m})$, a significant peak in cell number was observed in pore size of $120 \mu \mathrm{m}$ - similar to the findings of O'Brien et al. (2005). However, when this pore range was expanded the largest pore size facilitated the highest cell attachment even though specific surface area decreased (Murphy et al., 2012). One interpretation of these findings is that the lower peak results from optimising the specific surface area and attachment, but that a second peak emerges from an improved potential for cell migration and proliferation. More recent studies have examined the effect of pore size on long term tissue development. Siccheri et al. (2012) investigated tissue interaction in vivo within PLGA$\mathrm{CaP}$ scaffolds with pores in the range of 470-1200 $\mu \mathrm{m}$. Increased bone formation and vessel number was observed within pores in the range of $470-590 \mu \mathrm{m}$. Although this paper does not identify the lower limits of the optimal pore range for tissue formation, it is one of the first to identify an optimal pore range for tissue formation (Sicchieri et al., 2012).These papers reflect the first important step towards fully understanding the relationship between scaffold pore size and resultant cell and tissue behaviour.

Different cell types exhibit a preference for adhesion to scaffolds with different mean pore sizes, due to the characteristic size of the cell. When migrating through a porous network, cells use a bridging mechanism whereby they use neighbouring cells as support to bridge across pores larger than the individual cell (Salem et al., 2002). However, if pore size greatly exceeds the dimensions of a cell, the cell can only spread along the struts and this can influence cell migration and migration speed (Reilly and Engler, 2010). Lowery et al. (2010) highlighted these changes in cell conformation with changing pore size in woven polycaprolactone (PCL) scaffolds. As pore size increased, cells began to align along single fibres instead of attaching to multiple fibres (Lowery et al., 2010). Pore size within a scaffold determines the number of struts and the density of ligands available for cell adhesion. Thus, as pore size decreases there is more specific surface area for cell to adhere to (O'Brien et al., 2005). However, this denser network of struts limits choice in cells' direction of their movement and creates a greater resistance to scaffold penetration (Harley et al., 2008).

Speed is often the metric of choice to quantify the ability of cells to migrate (Lauffenburger and Horwitz, 1996; Ridley et al., 2003). However, it does not provide 

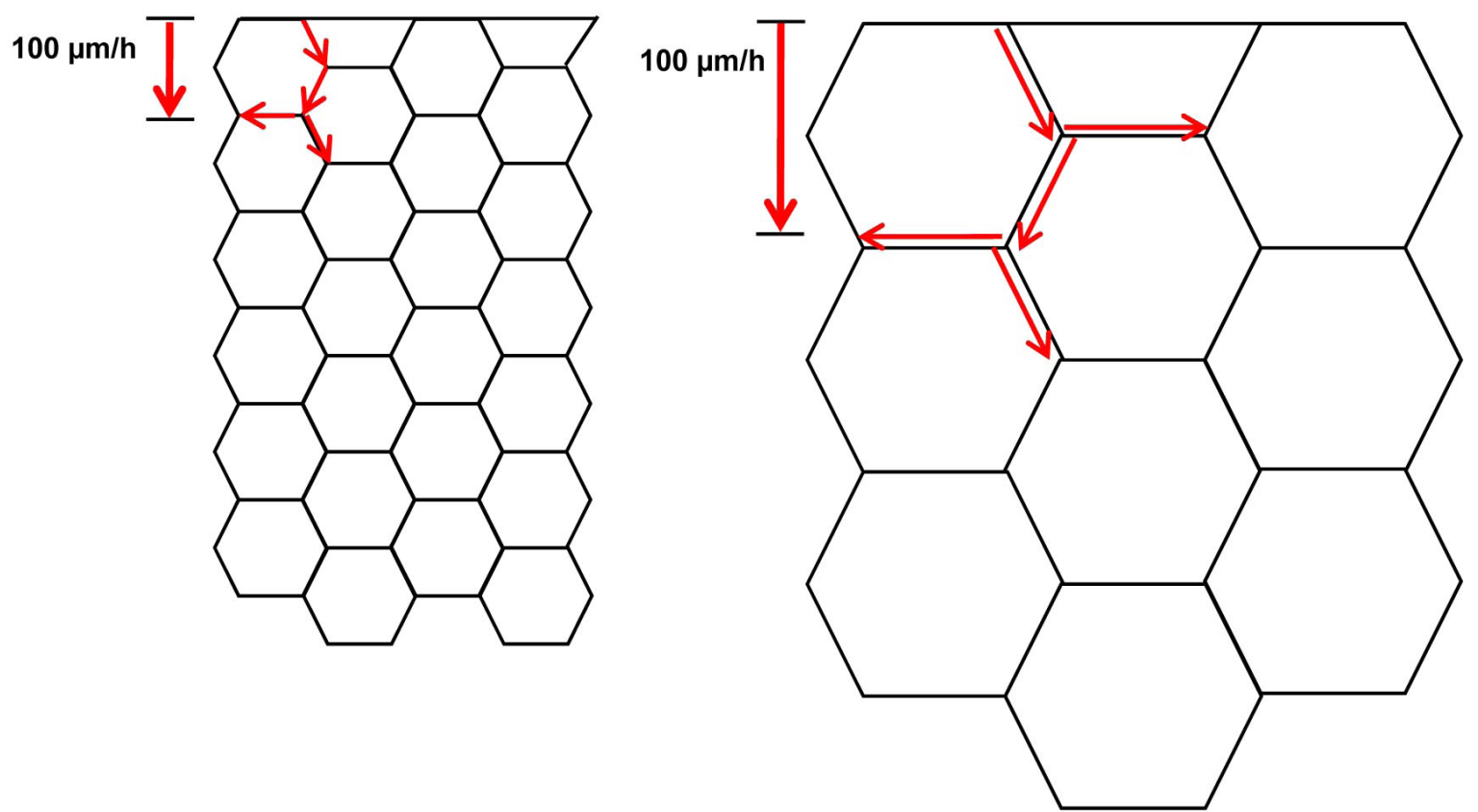

Fig. 2. Illustration on the effect of specific surface area in small pores (A) and large pores (B) on cell migration. Arrows indicate the direction of migration of cell and the distance travelled assuming the rate of cell migration is constant.

information about the direction or distribution of this motion (Zaman et al., 2007). Cells travelling through larger pores may migrate slower, but their directional movement allow them to travel further into the scaffold (Fig. 2). In summary, it has been shown that larger pore size can overcome the advantages of specific surface area by increased cell migration and scaffold infiltration (Murphy et al., 2010).

Scaffold porosity, the percentage void space within a solid (Karageorgiou and Kaplan, 2005), and pore size are intrinsically coupled. Whilst pore size is essential for cell attachment, proliferation and migration, porosity influences nutrient delivery and waste removal through a construct. It is generally accepted that the higher the porosity the better for construct development. Depending on the biomaterial used, an increase in porosity can lead to a decrease in mechanical properties. This is generally a greater concern in natural biomaterials such as collagen, alginate-based substrates and chitosan, as they are mechanically weaker materials. However, there are a number of crosslinking techniques that can be utilised to strengthen without affecting porosity (Haugh et al., 2009).

\section{Mechanical properties}

A scaffold's mechanical properties are derived from its composition and architecture. Beyond the previously discussed effects of scaffold architecture on cell migration, the capacity of a scaffold to respond to mechanical force can modulate the cellular response. These mechanoregulatory signals remain poorly understood, but may be an important consideration for future tissue engineering scaffold design.

Mechano-transduction is a process whereby cells transduce or convert physical force-induced signals into biochemical signals that are integrated into appropriate cellular responses (Ko and McCulloch, 2001; Huang et al., 2004). Numerous molecules, cellular components and extracellular structures have been shown to be involved in mechanochemical transduction. These transduction elements include cell-ECM and cell-cell adhesions, membrane components, cytoskeletal filaments and nuclear structures. A current challenge is trying to understand how cells orchestrate all these transduction mechanisms to produce specific responses to mechanical signals. Not all anchorage-dependent cells respond to substrate stiffness in the same way. However, MSCs, fibroblasts and endothelial cells have demonstrated increased cell adhesion, spreading and proliferation on stiffer substrates (Discher et al., 2005; Yeung et al., 2005). Cell migration has also shown to be influenced by stiffness gradients. Integrins provide a mechanical link between the ECM and the actomyosin cytoskeleton of cells. Integrins can trigger signalling transduction cascades and induce focal adhesion formations as a result of ECM ligand binding and associated changes in receptor conformation. Force application to bound integrins promotes focal adhesion assembly, which in turn promotes actin filament polymerisation and induces cytoskeletal contraction. Contractile forces are generated by the ubiquitous cross-bridging interactions of actin and myosin-II filaments in stress fibres (Fig 3A). These forces are transmitted to the substrate as traction forces. It is through these forces that cells are able sense their surrounding matrix and can distinguish subtle changes in matrix elasticity (Zajac and Discher, 2008). Although living cells might sense and respond to force locally through individual mechanosensitive molecules, they integrate physical and chemical signals at the whole cell level before they respond. As such, mechanical 


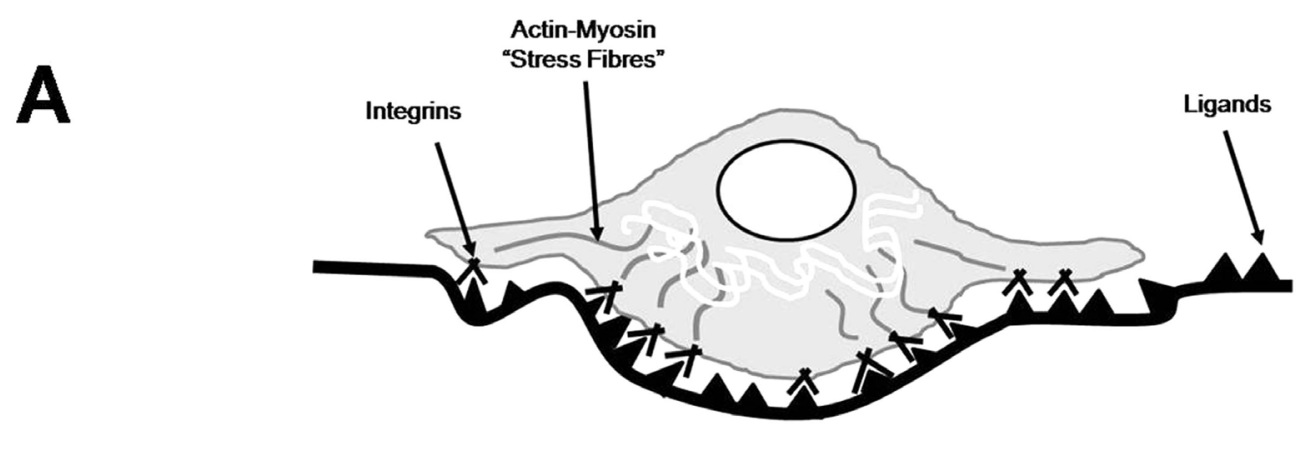

Soft Substrate

B

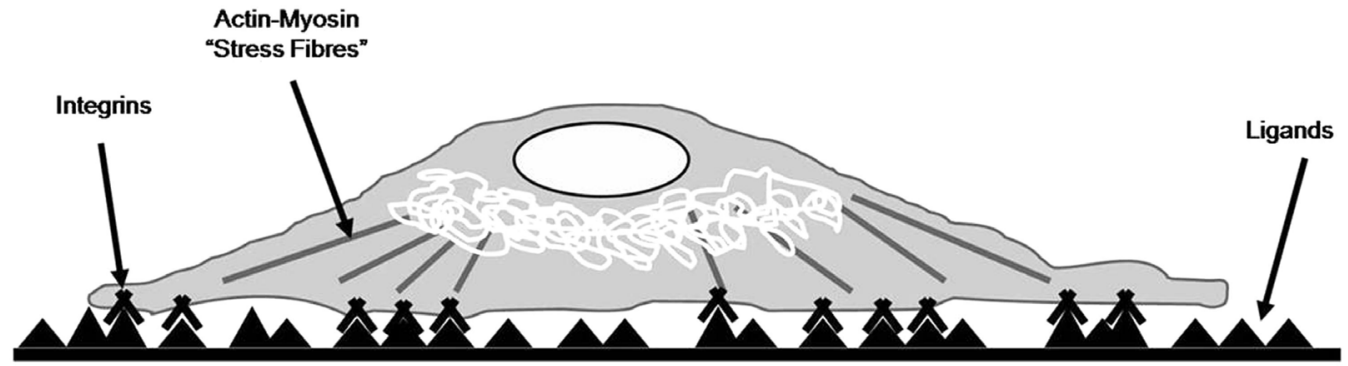

Stiff Substrate

C

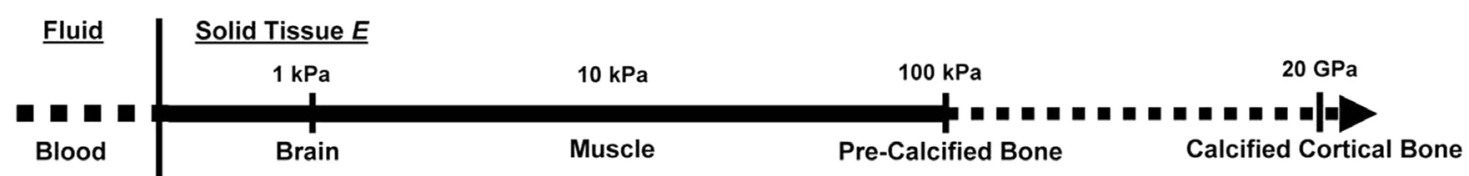

Fig. 3. Illustrations depicting the attachment of a cell to a soft $(\mathbf{A})$ and stiff $(\mathbf{B})$ substrate and the resultant cytoskeletal formations, adapted from Zajac et al. (2008).

forces generated with cell-ECM or cell-cell adhesions can influence embryogenesis and tissue formation (Evans et al., 2009). The mechanical properties of native tissues are very diverse and can vary, for example, from soft brain tissue $(0.1 \mathrm{kPa})$ to pre-calcified bone $(100 \mathrm{kPa})$ to rigid compact bone (20 GPa) (Fig. 3B) (Zysset et al., 1999; Flanagan et al., 2002). As such, naïve stem cells are exposed to a range of matrix elasticity in vivo.

In 2006, a study by Engler et al. indicated a key relationship between substrate stiffness and MSC differentiation whereby MSCs sense their surrounding matrix elasticity and transduce that information into morphological changes and lineage specification. Matrix elasticity was mimicked with inert polyacrylamide (PAAm) gels. Elasticity was altered via crosslinking with different concentrations of bis-acrylamide and adhesion was provided by collagen type I coating of the gels. Utilising this elastically tuneable system it was shown that matrix can specify the lineage of naïve stem cells towards neurons, myoblasts and osteoblasts respectively as stiffness increased. In addition, non-muscle myosin II (NM II) was identified as an integral component of the cell's ability to couple matrix stiffness to lineage specification (Engler et al., 2006). This study was the first to highlight importance of elasticity-directed differentiation as a novel and surprisingly sensitive cell regulator. Although once considered a cornerstone in literature for the effect substrate stiffness on stem cell fate, recent studies have demonstrated that there are other stem-cell-niche interactions guiding cell-substrate stiffness driven differentiation that must be taken into consideration. Trappmann et al. (2012) demonstrated that, similarly to the findings of Engler et al. (2006), MSC differentiation was regulated by the elastic modulus of PAAm gels. However, MSC differentiation was unaffected by polydimethylsiloxane (PDMS) gel stiffness. Furthermore, when PMDS gels were cultured with human epidermal stem cells, differentiation was unaffected. On PAAm gels, epidermal stem cell differentiation was only affected on gels of low elasticity (Trappmann et al., 2012). Similar to Engler et al. (2006), these gels were coated with collagen type I and changing the collagen crosslinking concentration altered stem cell differentiation on both gel types. Contradictory to previous findings, Trappmann et al. (2012) concluded that the feedback mechanism that drives cell-fate decisions is directed by the mechanical force exerted by the stem cells on the collagen fibres as opposed to the gels themselves. These studies demonstrate that stem cells-ECM mechano-forces and subsequent cell responses vary with differing cell types and substrates, highlighting the complicated nature of these interactions. 
Many of these studies have been carried out on polymer gels that do not recapitulate the normal 3D environment encountered by cells in porous engineered scaffolds. Recently, focus has shifted to changes sensed by cells within the elastic modulus of porous scaffolds (Murphy et al., 2012). Micro forces created by cellular contraction receive different mechanical-regulatory feedback, dependent on a scaffold's capacity for deformation. Previously, it has been shown that collagenGAG scaffold architecture influences the fate of MSCs whereby the stiffest collagen-GAG scaffolds $(1.5 \mathrm{kPa})$ directed naïve MSCs towards on osteogenic lineage and the most compliant collagen-GAG scaffolds $(0.5 \mathrm{kPa})$ directed the MSCs towards a chondrogenic lineage. It is interesting to note that the stiffness range utilised in this study is significantly limited in comparison to the studies carried out on 2-D substrates and gels. Yet, a significant influence on stem cell fate was observed (Murphy et al., 2012). This highlights the intricate relationship between cells and 3D porous scaffolds. What is determined as the elastic modulus of a whole scaffold, may not appropriately reflect the forces placed on a single cell on an individual struts (Harley et al., 2007). This area of research is still in its infancy and these mechano-biological relationships and the cell pathways they modulate need to be better understood, both in 2D and 3D environments, in order to manipulate stem cell differentiation for in vitro and clinical applications.

\section{Conclusions}

Tissue engineering is aimed at different applications, including implantation and drug delivery. Although individually important, success depends on the convergence of the three components of the tissue engineering triad. The utility of each component ultimately relies upon the criteria required for the specific application.

Subtle changes in scaffold architecture have significant effects on cellular activity. Interestingly, there is a dual relationship between scaffold pore size and cell behaviour. Increased surface area, provided by small pores, may have a beneficial effect on cell adhesion. However, improved cellular infiltration and migration, facilitated by larger pores, outweighs this effect. Recent advances in the cell biology of the ECM and ECM receptors have provided new and important ways of thinking about the interplay between cells and scaffolds, whereby scaffold mechanical properties and composition have been shown to influence integrin-ligand interactions, thus affecting cell morphology and differentiation. These fundamental studies have demonstrated the importance of tailoring scaffold microarchitecture, cell type and regulatory signals for tissuespecific applications.

In summary, continuing efforts are being made towards developing a clinically functioning tissue-engineered scaffold. Advancing our way of understanding and thinking about the interplay between cells and scaffolds will enhance our progression towards clinical applications.

\section{References}

Albrektsson T, Johansson C (2001) Osteoinduction, osteoconduction and osseointegration. Eur Spine J 10 Suppl 2: S96-101.

Arrington ED, Smith WJ, Chambers HG, Bucknell AL, Davino NA (1996) Complications of iliac crest bone graft harvesting. Clin Orthop Rel Res 329: 300-309.

Atala A, Bauer SB, Soker S, Yoo JJ, Retik AB (2006) Tissue-engineered autologous bladders for patients needing cystoplasty. Lancet 367: 1241-1246.

Babensee JE, Anderson JM, McIntire LV, Mikos AG (1998) Host response to tissue engineered devices. Adv Drug Deliv Rev 33: 111-139.

Barrere F, van Blitterswijk CA, de Groot K (2006) Bone regeneration: molecular and cellular interactions with calcium phosphate ceramics. Int J Nanomed 1: 317-332.

Berglund JD, Nerem RM, Sambanis A (2004) Incorporation of intact elastin scaffolds in tissueengineered collagen-based vascular grafts. Tissue Eng 10: 1526-1535.

Bishop AE, Buttery LD, Polak JM (2002) Embryonic stem cells. J Pathol 197: 424-429.

Bohner M, Galea L, Doebelin N (2012) Calcium phosphate bone graft substitutes: Failures and hopes. J Eur Ceram Soc 32: 2663-2671.

Bonewald LF, Mundy GR (1990) Role of transforming growth factor-beta in bone remodeling. Clin Orthop Relat Res 250: 261-276.

Caplan AI (2007) Adult mesenchymal stem cells for tissue engineering versus regenerative medicine. J Cell Physiol 213: 341-347.

Curtin CM, Cunniffe GM, Lyons FG, Bessho K, Dickson GR, Duffy GP, O'Brien FJ (2012) Innovative collagen nano-hydroxyapatite scaffolds offer a highly efficient non-viral gene delivery platform for stem cellmediated bone formation. Adv Mater 24: 749-754.

Damien CJ, Parsons JR (1991) Bone graft and bone graft substitutes: a review of current technology and applications. J Appl Biomateri 2: 187-208.

Darling EM, Athanasiou KA (2003) Biomechanical strategies for articular cartilage regeneration. Ann Biomed Eng 31: 1114-1124.

Discher DE, Janmey P, Wang Y-l (2005) Tissue cells feel and respond to the stiffness of their substrate. Science 310: 1139-1143.

Dragoo JL, Lieberman JR, Lee RS, Deugarte DA, Lee Y, Zuk PA, Hedrick MH, Benhaim P (2005) Tissueengineered bone from BMP-2-transduced stem cells derived from human fat. Plast Reconstr Surg 115: 16651673.

Engler AJ, Sen S, Sweeney HL, Discher DE (2006) Matrix elasticity directs stem cell lineage specification. Cell 126: 677-689.

Evans ND, Minelli C, Gentleman E, LaPointe V, Patankar SN, Kallivretaki M, Chen X, Roberts CJ, Stevens MM (2009) Substrate stiffness affects early differentiation events in embryonic stem cells. Eur Cell Mater 18: 13-14.

Flanagan LA, Ju Y-E, Marg B, Osterfield M, Janmey PA (2002) Neurite branching on deformable substrates. Neuroreport 13: 2411. 
Fraser JK, Zhu M, Wulur I, Alfonso Z (2008) Adiposederived stem cells. Methods Mol Biol 449: 59-67.

Friedl P, Zanker KS, Brocker EB (1998) Cell migration strategies in 3-D extracellular matrix: differences in morphology, cell matrix interactions, and integrin function. Microsc Res Tech 43: 369-378.

Gao C, Seuntjens J, Kaufman GN, Tran-Khanh N, Butler A, Li A, Wang H, Buschmann MD, Harvey EJ, Henderson JE (2012) Mesenchymal stem cell transplantation to promote bone healing. J Orthop Res 30: 1183-1189.

Geiger M, Li RH, Friess W (2003) Collagen sponges for bone regeneration with rhBMP-2. Adv Drug Deliv Rev 55: 1613-1629.

Giannoudis PV, Dinopoulos H, Tsiridis E (2005) Bone substitutes: an update. Injury 36 Suppl 3: S20-27.

Gleeson JP, Plunkett NA, O’Brien FJ (2010) Addition of hydroxyapatite improves stiffness, interconnectivity and osteogenic potential of a highly porous collagen-based scaffold for bone tissue regeneration. Eur Cells Mater 20: 218-230.

Glowacki J, Mizuno S (2008) Collagen scaffolds for tissue engineering. Biopolymers 89: 338-344.

Godbey WT, Atala A (2002) In vitro systems for tissue engineering. Ann NY Acad Sci, 961: 10-26.

Govender S, Csimma C, Genant HK, Valentin-Opran A, Amit Y, Arbel R, Aro H, Atar D, Bishay M, Borner MG, Chiron P, Choong P, Cinats J, Courtenay B, Feibel R, Geulette B, Gravel C, Haas N, Raschke M, Hammacher E, van der Velde D, Hardy P, Holt M, Josten C, Ketterl RL, Lindeque B, Lob G, Mathevon H, McCoy G, Marsh D, Miller R, Munting E, Oevre S, Nordsletten L, Patel A, Pohl A, Rennie W, Reynders P, Rommens PM, Rondia J, Rossouw WC, Daneel PJ, Ruff S, Ruter A, Santavirta S, Schildhauer TA, Gekle C, Schnettler R, Segal D, Seiler H, Snowdowne RB, Stapert J, Taglang G, Verdonk R, Vogels L, Weckbach A, Wentzensen A, Wisniewski T (2002) Recombinant human bone morphogenetic protein-2 for treatment of open tibial fractures: a prospective, controlled, randomized study of four hundred and fifty patients. J Bone Joint Surg [Am] 84-A: 2123-2134.

Griffith LG, Naughton G (2002) Tissue engineering current challenges and expanding opportunities. Science 295: 1009-1014.

Gumbiner BM (1996) Cell adhesion: the molecular basis of tissue architecture and morphogenesis. Cell 84: 345-357.

Harley BA, Freyman TM, Wong MQ, Gibson LJ (2007) A new technique for calculating individual dermal fibroblast contractile forces generated within collagenGAG scaffolds. Biophys J 93: 2911-2922.

Harley BA, Kim HD, Zaman MH, Yannas IV, Lauffenburger DA, Gibson LJ (2008) Microarchitecture of three-dimensional scaffolds influences cell migration behavior via junction interactions. Biophys J 95: 40134024.

Haugh MG, Jaasma MJ, O’Brien FJ (2009) The effect of dehydrothermal treatment on the mechanical and structural properties of collagen-GAG scaffolds. J Biomed Materi Res A 89: 363-369.
Haugh MG, Murphy CM, McKiernan RC, Altenbuchner C, O’Brien FJ (2011) Crosslinking and mechanical properties significantly influence cell attachment, proliferation, and migration within collagen glycosaminoglycan scaffolds. Tissue Eng A 17: 1201-1208.

Heino J (2000) The collagen receptor integrins have distinct ligand recognition and signaling functions. Matrix Biol: 19: 319-323.

Hipp J, Atala A (2008) Sources of stem cells for regenerative medicine. Stem Cell Rev 4: 3-11.

Hoffman AS (2012) Hydrogels for biomedical applications. Adv Drug Deliv Rev 64 Suppl: 18-23.

Huang H, Kamm RD, Lee RT (2004) Cell mechanics and mechanotransduction: pathways, probes, and physiology. Am J Physiol Cell Physiol 287: C1-11.

Hubbell JA (1995) Biomaterials in tissue engineering. Biotechnology (N Y) 13: 565-576.

Hulbert SF, Young FA, Mathews RS, Klawitter JJ, Talbert CD, Stelling FH (1970) Potential of ceramic materials as permanently implantable skeletal prostheses. J Biomed Mater Res 4: 433-456.

Hutmacher DW (2000) Scaffolds in tissue engineering bone and cartilage. Biomaterials 21: 2529-2543.

Huttenlocher A, Ginsberg MH, Horwitz AF (1996) Modulation of cell migration by integrin-mediated cytoskeletal linkages and ligand-binding affinity. J Cell Biol 134: 1551-1562.

Huttenlocher A, Sandborg RR, Horwitz AF (1995) Adhesion in cell migration. Curr Opin Cell Biol 7: 697-706.

Hynes RO (1987) Integrins: a family of cell surface receptors. Cell 48: 549-554.

Jiang T, Abdel-Fattah WI, Laurencin CT (2006) In vitro evaluation of chitosan/poly(lactic acid-glycolic acid) sintered microsphere scaffolds for bone tissue engineering. Biomaterials 27: 4894-4903.

Kanatani M, Sugimoto T, Fukase M, Fujita T (1991) Effect of elevated extracellular calcium on the proliferation of osteoblastic MC3T3-E1 cells:its direct and indirect effects via monocytes. Biochem Biophys Res Commun 181: 1425-1430.

Kanungo BP, Gibson LJ (2010) Density-property relationships in collagen-glycosaminoglycan scaffolds. Acta Biomater 6: 344-353.

Karageorgiou V, Kaplan D (2005) Porosity of 3D biomaterial scaffolds and osteogenesis. Biomaterials 26: 5474-5491.

Kelly DJ, Prendergast PJ (2004) Effect of a degraded core on the mechanical behaviour of tissue-engineered cartilage constructs: a poro-elastic finite element analysis. Med Biol Eng Comput 42: 9-13.

Keogh MB, O’Brien FJ, Daly JS (2010) Substrate stiffness and contractile behaviour modulate the functional maturation of osteoblasts on a collagen-GAG scaffold. Acta Biomater 6: 4305-4313.

Kern S, Eichler H, Stoeve J, Kluter H, Bieback K (2006) Comparative analysis of mesenchymal stem cells from bone marrow, umbilical cord blood, or adipose tissue. Stem Cells 24: 1294-1301.

Khan SN, Cammisa FP, Jr., Sandhu HS, Diwan AD, Girardi FP, Lane JM (2005) The biology of bone grafting. J Am Acad Orthop Surg 13: 77-86. 
Kilian O, Flesch I, Wenisch S, Taborski B, Jork A, Schnettler R, Jonuleit T (2004) Effects of platelet growth factors on human mesenchymal stem cells and human endothelial cells in vitro. Eur J Med Res 9: 337-344.

Kim BG, Kang YM, Phi JH, Kim YH, Hwang DH, Choi JY, Ryu S, Elastal AE, Paek SH, Wang KC, Lee SH, Kim SU, Yoon BW (2010) Implantation of polymer scaffolds seeded with neural stem cells in a canine spinal cord injury model. Cytotherapy 12: 841-845.

Kim IY, Seo SJ, Moon HS, Yoo MK, Park IY, Kim BC, Cho CS (2008) Chitosan and its derivatives for tissue engineering applications. Biotechnol Adv 26: 1-21.

Ko KS, McCulloch CA (2001) Intercellular mechanotransduction: cellular circuits that coordinate tissue responses to mechanical loading. Biochem Biophys Res Commun 285: 1077-1083.

Krampera M, Pizzolo G, Aprili G, Franchini M (2006) Mesenchymal stem cells for bone, cartilage, tendon and skeletal muscle repair. Bone 39: 678-683.

Lauffenburger DA, Horwitz AF (1996) Cell migration: A physically integrated molecular process. Cell 84: 359 369.

Lee CR, Grodzinsky AJ, Hsu HP, Spector M (2003) Effects of a cultured autologous chondrocyte-seeded type II collagen scaffold on the healing of a chondral defect in a canine model. J Orthop Res 21: 272-281.

Lee CR, Grodzinsky AJ, Spector M (2001) The effects of cross-linking of collagen-glycosaminoglycan scaffolds on compressive stiffness, chondrocyte-mediated contraction, proliferation and biosynthesis. Biomaterials 22: 3145-3154.

Lee SJ, Lee IW, Lee YM, Lee HB, Khang G (2004) Macroporous biodegradable natural/synthetic hybrid scaffolds as small intestine submucosa impregnated poly(D,L-lactide-co-glycolide) for tissue-engineered bone. J Biomaters Sci Polymer ed 15: 1003-1017.

Levenberg S, Huang NF, Lavik E, Rogers AB, Itskovitz-Eldor J, Langer R (2003) Differentiation of human embryonic stem cells on three-dimensional polymer scaffolds. Proc Natl SAcad Sci USA 100: 12741-12746.

Lowery JL, Datta N, Rutledge GC (2010) Effect of fiber diameter, pore size and seeding method on growth of human dermal fibroblasts in electrospun poly(epsiloncaprolactone) fibrous mats. Biomaterials 31: 491-504.

Ma L, Gao C, Mao Z, Zhou J, Shen J (2004) Enhanced biological stability of collagen porous scaffolds by using amino acids as novel cross-linking bridges. Biomaterials 25: 2997-3004.

Macchiarini P, Jungebluth P, Go T, Asnaghi MA, Rees LE, Cogan TA, Dodson A, Martorell J, Bellini S, Parnigotto PP, Dickinson SC, Hollander AP, Mantero S, Conconi MT, Birchall MA (2008) Clinical transplantation of a tissueengineered airway. Lancet 372: 2023-2030.

Metsger DS, DePhilip RM, Hayes TG (1993) An autoradiographic study of calcium phosphate ceramic bone implants in turkeys. Clinical Orthop Rel Res 291: 283-294.

Moutos FT, Freed LE, Guilak F (2007) A biomimetic three-dimensional woven composite scaffold for functional tissue engineering of cartilage. Nat Mater 6: 162-167.
Mueller SM, Glowacki J (2001) Age-related decline in the osteogenic potential of human bone marrow cells cultured in three-dimensional collagen sponges. J Cell Biochem 82: 583-590.

Murphy CM, Haugh MG, O’Brien FJ (2010) The effect of mean pore size on cell attachment, proliferation and migration in collagen-glycosaminoglycan scaffolds for bone tissue engineering. Biomaterials 31: 461-466.

Murphy CM, Matsiko A, Haugh MG, Gleeson JP, O'Brien FJ (2012) Mesenchymal stem cell fate is regulated by the composition and mechanical properties of collagenglycosaminoglycan scaffolds. J Mech Behav Biomed Mater 11: $53-62$.

Murphy CM, O’Brien FJ (2010) Understanding the effect of mean pore size on cell activity in collagenglycosaminoglycan scaffolds. Cell Adh Migr 4: 377-381.

Murphy WL, Peters MC, Kohn DH, Mooney DJ (2000) Sustained release of vascular endothelial growth factor from mineralized poly(lactide-co-glycolide) scaffolds for tissue engineering. Biomaterials 21: 2521-2527.

Musina RA, Bekchanova ES, Belyavskii AV, Grinenko TS, Sukhikh GT (2007) Umbilical cord blood mesenchymal stem cells. Bull Exp Biol Med 143: 127-131.

Nehrer S, Breinan HA, Ramappa A, Young G, Shortkroff S, Louie LK, Sledge CB, Yannas IV, Spector M (1997) Matrix collagen type and pore size influence behaviour of seeded canine chondrocytes. Biomaterials 18: 769-776.

Nishida S, Endo N, Yamagiwa H, Tanizawa T, Takahashi HE (1999) Number of osteoprogenitor cells in human bone marrow markedly decreases after skeletal maturation. J Bone Miner Metab 17: 171-177.

Numata K, Kaplan DL (2010) Silk-based delivery systems of bioactive molecules. Adv Drug Deliv Rev 62: 1497-1508.

O'Brien FJ (2011) Biomaterials and scaffolds for tissue engineering. MaterToday 14: 88-95.

O’Brien FJ, Harley BA, Yannas IV, Gibson LJ (2005) The effect of pore size on cell adhesion in collagen-GAG scaffolds. Biomaterials 26: 433-441.

O’Rorke S, Keeney M, Pandit A (2010) Non-viral polyplexes: Scaffold mediated delivery for gene therapy. Progr Polymer Sci 35: 441-458.

Panyam J, Labhasetwar V (2012) Biodegradable nanoparticles for drug and gene delivery to cells and tissue. Adv Drug Deliv Rev 64 Suppl: 61-71.

Pilliar RM, Filiaggi MJ, Wells JD, Grynpas MD, Kandel RA(2001) Porous calcium polyphosphate scaffolds for bone substitute applications - in vitro characterization. Biomaterials 22: 963-972.

Pittenger MF, Mackay AM, Beck SC, Jaiswal RK, Douglas R, Mosca JD, Moorman MA, Simonetti DW, Craig S, Marshak DR (1999) Multilineage potential of adult human mesenchymal stem cells. Science 284: 143-147.

Plunkett NA, O’Brien FJ (2011) Bioreactors in tissue engineering. Technol Health Care 19: 55-69.

Potter W, Kalil RE, Kao WJ (2008) Biomimetic material systems for neural progenitor cell-based therapy. Front Biosci 13: 806-821. 
Radisic M, Park H, Chen F, Salazar-Lazzaro JE, Wang Y, Dennis R, Langer R, Freed LE, Vunjak-Novakovic G (2006) Biomimetic approach to cardiac tissue engineering: oxygen carriers and channeled scaffolds. Tissue Eng 12: 2077-2091.

Ravindran S, Song Y, George A (2010) Development of three-dimensional biomimetic scaffold to study epithelialmesenchymal interactions. Tissue Eng A 16: 327-342.

Reilly GC, Engler AJ (2010) Intrinsic extracellular matrix properties regulate stem cell differentiation. J Biomech 43: 55-62.

Ridley AJ, Schwartz MA, Burridge K, Firtel RA, Ginsberg MH, Borisy G, Parsons JT, Horwitz AR (2003) Cell migration: integrating signals from front to back. Science 302: 1704-1709.

Rippon HJ, Bishop AE (2004) Embryonic stem cells. Cell Prolif 37: 23-34.

Rizzi SC, Heath DJ, Coombes AG, Bock N, Textor M, Downes S (2001) Biodegradable polymer/hydroxyapatite composites: surface analysis and initial attachment of human osteoblasts. J Biomed Mater Res, 55: 475-486.

Rose FR, Oreffo RO (2002) Bone tissue engineering: hope vs. hype. Biochem Biophys Res Commun 292: 1-7.

Salem AK, Stevens R, Pearson RG, Davies MC, Tendler SJ, Roberts CJ, Williams PM, Shakesheff KM (2002) Interactions of 3T3 fibroblasts and endothelial cells with defined pore features. J Biomed Mater Res 61: 212-217.

Shin H, Jo S, Mikos AG (2002) Modulation of marrow stromal osteoblast adhesion on biomimetic oligo[poly(ethylene glycol) fumarate] hydrogels modified with Arg-Gly-Asp peptides and a poly(ethyleneglycol) spacer. J. Biomed. Mater. Res 61: 169-179.

Shin H, Jo S, Mikos AG (2003) Biomimetic materials for tissue engineering. Biomaterials 24: 4353-4364.

Sicchieri LG, Crippa GE, de Oliveira PT, Beloti MM, Rosa AL (2012) Pore size regulates cell and tissue interactions with PLGA-CaP scaffolds used for bone engineering. J Tissue Eng Regen Med 6: 155-162.

Stenderup K, Justesen J, Clausen C, Kassem M (2003) Aging is associated with decreased maximal life span and accelerated senescence of bone marrow stromal cells. Bone 33: 919-926.

Storrie H, Mooney DJ (2006) Sustained delivery of plasmid DNA from polymeric scaffolds for tissue engineering. Adv Drug Deliv Rev 58: 500-514.

Takahashi K, Yamanaka S (2006) Induction of pluripotent stem cells from mouse embryonic and adult fibroblast cultures by defined factors. Cell 126: 663-676.

Thomson JA, Itskovitz-Eldor J, Shapiro SS, Waknitz MA, Swiergiel JJ, Marshall VS, Jones JM (1998) Embryonic stem cell lines derived from human blastocysts. Science 282: 1145-1147.

Tierney CM, Haugh MG, Liedl J, Mulcahy F, Hayes B, O'Brien FJ (2009a) The effects of collagen concentration and crosslink density on the biological, structural and mechanical properties of collagen-GAG scaffolds for bone tissue engineering. J Mech Behav Biomed Mater 2: 202209.

Tierney CM, Jaasma MJ, O’Brien FJ (2009b) Osteoblast activity on collagen-GAG scaffolds is affected by collagen and GAG concentrations. J Biomed Mater Res A 91: 92-101.

Tierney EG, Duffy GP, Hibbitts AJ, Cryan SA, O’Brien FJ (2012a) The development of non-viral gene-activated matrices for bone regeneration using polyethyleneimine (PEI) and collagen-based scaffolds. J Control Release 158: 304-311.

Tierney EG, McSorley K, Hastings CL, Cryan SA, O'Brien T, Murphy MJ, Barry FP, O’Brien FJ, Duffy GP (2012b) High levels of ephrinB2 over-expression increases the osteogenic differentiation of human mesenchymal stem cells and promotes enhanced cell mediated mineralisation in a polyethyleneimine-ephrinB2 gene-activated matrix. J Control Release 165: 173-182.

Timmins NE, Scherberich A, Fruh JA, Heberer M, Martin I, Jakob M (2007) Three-dimensional cell culture and tissue engineering in a T-CUP (tissue culture under perfusion). Tissue Eng 13: 2021-2028.

Trappmann B, Gautrot JE, Connelly JT, Strange DG, Li Y, Oyen ML, Cohen Stuart MA, Boehm H, Li B, Vogel V, Spatz JP, Watt FM, Huck WT (2012) Extracellular-matrix tethering regulates stem-cell fate. Nat Mater 11: 642-649.

Uccelli A, Moretta L, Pistoia V (2008) Mesenchymal stem cells in health and disease. Nat Rev Immunol, 8: 726-736.

Vepari C, Kaplan DL (2007) Silk as a biomaterial. Progr Polymer Sci 32: 991-1007.

Williams JM, Adewunmi A, Schek RM, Flanagan CL, Krebsbach PH, Feinberg SE, Hollister SJ, Das S (2005) Bone tissue engineering using polycaprolactone scaffolds fabricated via selective laser sintering. Biomaterials 26: 4817-4827.

Yang S, Leong KF, Du Z, Chua CK (2001) The design of scaffolds for use in tissue engineering. Part I. Traditional factors. Tissue Eng. 7: 679-689.

Yannas IV (2001) Tissue and organ regeneration in adults. Springer, New York.

Yannas IV, Lee E, Orgill DP, Skrabut EM, Murphy GF (1989) Synthesis and characterization of a model extracellular matrix that induces partial regeneration of adult mammalian skin. Proc Natl Acad Sci USA 86: 933937.

Yeung T, Georges PC, Flanagan LA, Marg B, Ortiz M, Funaki M, Zahir N, Ming W, Weaver V, Janmey PA (2005) Effects of substrate stiffness on cell morphology, cytoskeletal structure, and adhesion. Cell Motil Cytoskel 60: 24-34.

Yu J, Vodyanik MA, Smuga-Otto K, AntosiewiczBourget J, Frane JL, Tian S, Nie J, Jonsdottir GA, Ruotti V, Stewart R (2007) Induced pluripotent stem cell lines derived from human somatic cells. Science 318: $1917-$ 1920.

Zaidi M, Datta HK, Patchell A, Moonga B, MacIntyre I (1989) 'Calcium-activated' intracellular calcium elevation: a novel mechanism of osteoclast regulation. Biochem Biophys Res Commun163: 1461-1465.

Zajac AL, Discher DE (2008) Cell differentiation through tissue elasticity-coupled, myosin-driven remodeling. Curr Opin Cell Biol 20: 609-615.

Zaman MH, Matsudaira P, Lauffenburger DA (2007) Understanding effects of matrix protease and matrix 
organization on directional persistence and translational speed in three-dimensional cell migration. Ann Biomed Eng 35: 91-100.

Zeltinger J, Sherwood JK, Graham DA, Mueller R, Griffith LG (2001) Effect of pore size and void fraction on cellular adhesion, proliferation, and matrix deposition. Tissue Eng 7: 557-572.

Zhang WY, de Almeida PE, Wu JC (2008) Teratoma formation: A tool for monitoring pluripotency in stem cell research. In: StemBook (Girard L, ed), Harvard Stem Cell Institute, Cambridge, MA.

Zuk PA, Zhu M, Ashjian P, De Ugarte DA, Huang JI, Mizuno H, Alfonso ZC, Fraser JK, Benhaim P, Hedrick
MH (2002) Human adipose tissue is a source of multipotent stem cells. Mol Biol Cell 13: 4279-4295.

Zysset PK, Guo XE, Hoffler CE, Moore KE, Goldstein SA (1999) Elastic modulus and hardness of cortical and trabecular bone lamellae measured by nanoindentation in the human femur. J Biomech 32: 1005-1012.

Editor's note: All questions from the reviewers were answered by text changes. There is hence no "Discussion with Reviewers" section. 